\title{
Alternative UV Sensors Based on Color-Changeable Pigments
}

\author{
Martina Vikova, Michal Vik \\ Departmentof Textile Chemistry, Technical University of Liberec, Liberec, Czech Republic \\ E-mail: \{martina.vikova,michal.vik\}@tul.cz \\ Recieved August 16, 2011; revised September 7, 2011; accepted September 20, 2011
}

\begin{abstract}
Photochromism is a chemical process in which a compound undergoes a reversible change between two states having separate absorption spectra, i.e. different color [1]. In our previous work we have published some solutions of problems of measuring photochromic textile sample by standard commercial spectrophotometric systems [2]. Main problem with measurement of kinetic behavior of photochromic pigments by standard spectrophotometer is relatively long time period between individual measurements $(5 \mathrm{~s})$ and impossibility of measuring whole color change during exposure without interruption of illumination of sample during measurement. It means, standard commercial spectrophotometers enable off-line measurement of kinetic behavior during exposure period and quasi on-line measurement during reversion period. Based on this problem, it is only possible to obtain precise data during reversion-decay process and growth process (exposure) is affected by high variability of data. Following this knowledge, we developed original experimenttal system with short time scanning of color change of photochromic samples during growth and decay period of color change. In this study it is presented new view on the relationship between intensity of UV-A radiation and color change half-life $t_{1 / 2}$. Via this relation, it is demonstrated the possibility of the flexible textile-based sensors construction in the area of the radiation intensity identification.
\end{abstract}

Keywords: UV Radiation, Photochromism, Spectrophotometer, Textile, Sensor

\section{Introduction}

It is well known, that ozone depletion in the earth's atmosphere has made the headlines on many occasions and most people would be aware of the significant problem that exists. Sunburn, skin cancer, premature aging, and suppression of the immune system are some of the harmful effects of acute and cumulative exposure to ultraviolet radiation (UVR). A decrease of $1 \%$ in ozone would lead to increases in the solar UVR at the earth's surface and may eventually lead to a $2.3 \%$ increase in skin cancer. Preventing the damages of UV-rays caused by exposure to sunlight is difficult. Most of the health problems due to UV-rays are not visible on a short issue, and so, there is a feeling that there is no risk, except sunburns by staying for a long time in the sun [3-5]. An easy to understand and use UV-sensor would help people know what exact protection they need according to the amount of UV they are exposed to.

The idea of this work is to create a two part flexible UV-sensitive measurement device. One part would be the UV-sensitive area, changing color when exposed to sunlight, which contains in its spectrum the wavelengths of UV-rays, and a colored scale ( 4 or 5 steps scale), corresponding to different amounts of UV-intensity. When exposed to the sunlight, the UV-sensitive part would change color. By comparison with the stable part-the scale - it would indicate the user the amount of UV-radiations he is exposed to in the form of health protection advices, letting him know when some extra protection is required (wearing a t-shirt, put sunscreen on...) or if the sun exposure should simply be stopped after a certain time in the sun.

Color-changeable part of UV textile sensor is based on application of the photochromic pigments. "Photochromism is a reversible transformation of a chemical species induced in one or both directions by absorption of electromagnetic radiation between two forms, A and B, having different absorption spectra" [6-8].

Figure 1 shows that the thermodynamically stable form A is transformed by irradiation into form $\mathbf{B}$. The back reaction can occur thermally (Photochromism of type $\mathbf{T}$ ) or 


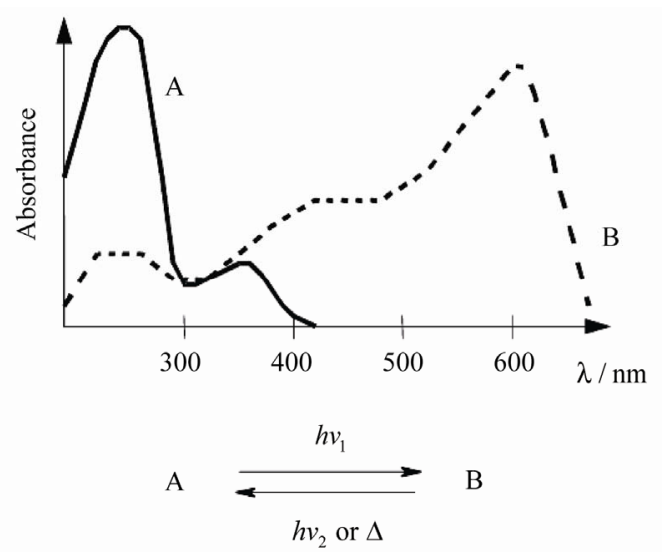

Figure 1. Difference in absorption spectra between two forms of photochromic specie.

photo chemically (Photochromism of type $\mathbf{P}$ ). The most prevalent organic photochromic systems involve unimolecular reactions: the most common photochromic molecules have a colorless or pale yellow form $\mathbf{A}$ and a colored form B (e.g., yellow, red, violet, green or blue). This phenomenon is referred to as positive photochromism [9]. Other systems are bimolecular, such as those involving photocycloaddition reactions. When $\lambda_{\max }(\mathbf{A})>\lambda_{\max }(\mathbf{B})$, photochromism is negative or inverse.

The unimolecular processes are encountered, for example, with spiropyrans, a family of molecules that has been studied extensively [10-22]. Solid photochromic spiropyrans or solutions (in ethanol, toluene, ether, ketone, esters, etc.) are colorless or weakly colored. Upon UV irradiation, they become colored. The colored solutions fade thermally to their original state; in many cases, they can also be decolorized (bleached) by visible light.

In general, the photochromic processes involve a onephoton mechanism $[23,24]$. $\mathbf{B}$ is formed from the singlet $\left(1 \mathbf{A}^{*}\right)$ or triplet $\left(3 \mathbf{A}^{*}\right)$ excited states or both. $\mathbf{B}$, the photoproduct, may also be formed from an upper excited state populated by absorption of two photons.

Figure 2 describes two-photon photochromism [25-27]. The transition probability to populate the final state (hence to obtain the photoproduct) depends on the product of the photon irradiances $E p(1)$ and $E p(2)$ of the two excit

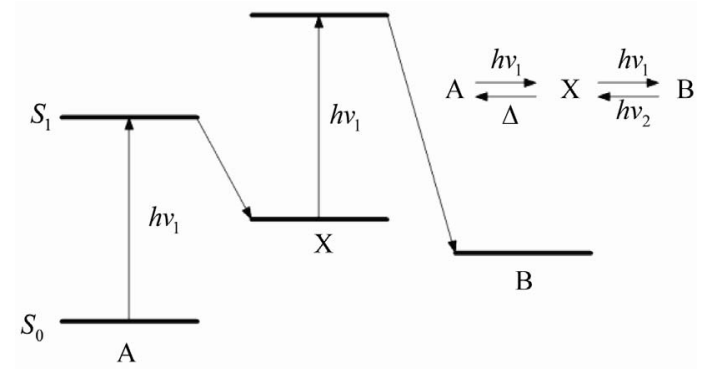

Figure 2. Stepwise two-photon photochromic reaction. ing beams. It is, therefore, advantageous to utilize lasers emitting high photon irradiance, such as those generating picoseconds or sub-picoseconds pulses. Two absorption processes may be distinguished:

- Simultaneous absorption of two photons via a virtual level.

- Stepwise (or sequential) two-photon absorption where the second photon absorption takes place from a real level.

The determination of the photochromic parameters, such as the number, nature, and kinetic and spectral properties of the transient species formed under irradiation is not a trivial task because the photoproducts are too labile to be isolated in many cases [28]. As an illustration, the kinetic behavior of the unimolecular systems is considered (e.g., spiropyrans, spiroxazines, dihydroindolizines, which are of major importance for applications to ophthalmic lenses) [29].

Under continuous monochromatic irradiation, a photochromic system can be considered to be at no equilibrium and open. The evolution of the concentrations of the reacting species (starting compounds, photo isomers, and degradation products) can be described by an appropriate set of differential equations. The only simplifying hypothesis that is used for their establishment is that the well-stirred mixture obeys Beer's law; nevertheless in color science is obviously used Kubelka-Munk function, because measured media are turbid [30,31]. Kubelka-Munk function, as well as Beer's law, is monochromatic. For description of kinetic behavior of photochromic samples we used first order kinetic model as is shown in following equations [32]:

$$
K / S_{(t)}=\left(K / S_{(0)}-K / S_{(\infty)}\right) \exp (-k t)+K / S_{(\infty)}
$$

where:

$K$ is the Absorption Coefficient $\equiv$ the limiting fraction of absorption of light energy per unit thickness, as thickness becomes very small.

$S$ is the Scattering Coefficient $\equiv$ the limiting fraction of light energy scattered backwards, subscript defines time relationship: $(t)$ - actual time, (0) - time on the beginningand, $(\infty)$ - time in infinity.

$k$ is rate constant and $t$ time.

In Figure 3, the main levels of shade intensity $\left(I_{0}, I_{\infty}, I_{1 / 2}\right)$ are shown. Shade intensity $I$ is calculated from Equation (2):

$$
I=\int_{360}^{780}(K / S)_{\lambda} \mathrm{d} \lambda
$$

Special attention is given to the half shade intensity $I_{1 / 2}$, because this value is related to the half-life of the photochromic reaction, the half-life of photochromic color change $t_{1 / 2}$. The half-life of photochromic color change $\boldsymbol{t}_{1 / 2}$ is a measured of the rate of the color change and is calculated based on Equation (3): 


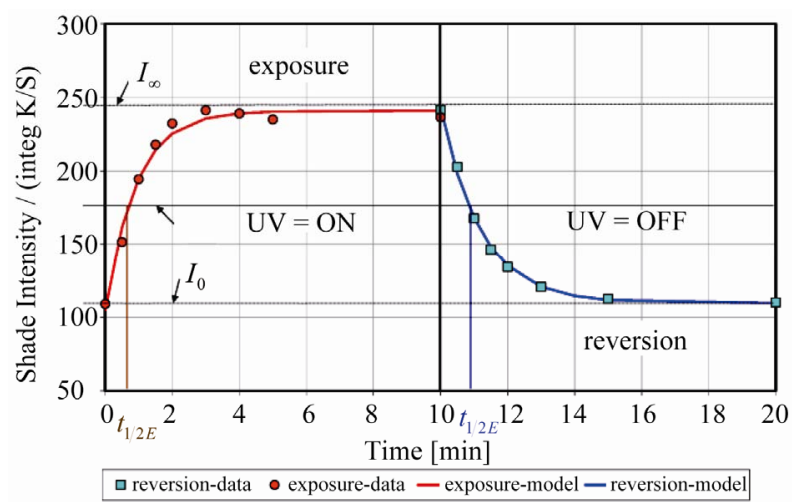

Figure 3. Evolution of reflectance under continuous irradiation and decay of reflectance when irradiance is stopped.

$$
t_{1 / 2}=\frac{\ln 2}{k}[s]
$$

\section{Materials and Methods}

Main task of our research work is to develop a simple textile sensor, which is sensitive to UV light and kinetic study of behaviour and main attention was given to possibility use the technology of textile printing by screen printing-PTP. For experiment were used five commercial photochromic pigments P1-P5. Examples of chemical structure are given in Figures 4-8.

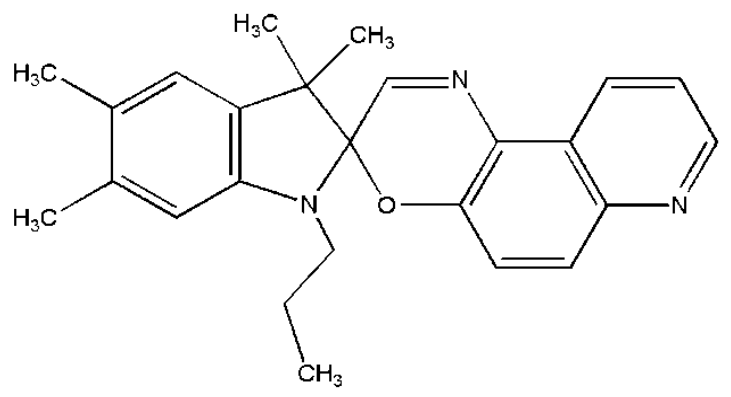

Figure 4. 3,3,5,6-Tetramethyl-1-propylspiro [indoline-2,3' $[3 \mathrm{H}]$ pyrido [3,2-f][1,4]benzoxazine] (P1).<smiles>COc1ccc(-c2c(OC(C)=O)c3c(c4cc(OC)ccc24)OC(c2ccc(OC)cc2)(c2ccc(OC)cc2)C=C3)cc1</smiles>

Figure 5. Methyl 2,2,6-tris(4-methoxyphenyl)-9-methoxy2H-naphtho-[1,2-b]pyran-5-carboxylate (P2).<smiles>COc1ccc(C2(c3ccc(OC)cc3)C=Cc3c(c(OC(C)=O)c(OC(C)=O)c4ccccc34)O2)cc1</smiles>

Figure 6. Methyl 2,2-bis(4-methoxyphenyl)-6-acetoxy-2Hnaphtho-[1,2-b]pyran-5-carboxylate (P3).<smiles>Cc1cc2c(cc1C)C(C)(C)C1(C=Nc3c(ccc4ccccc34)O1)N2C</smiles>

Figure 7. 1,3,3,5,6-Pentamethyl(indoline-2,3'-[3H] naphtho [2,1-b] [1,4] oxazine) (P4).

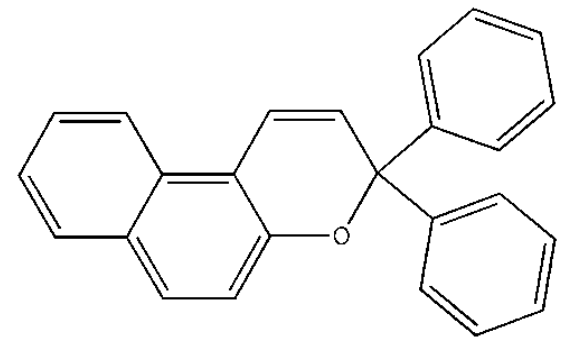

Figure 8. 3,3-Diphenyl-3H-naphtho[2,1-b]pyran(P5).

In our previous work we have published some solutions of problems of measuring photochromic textile sample by standard spectrophotometer system [33]. Main problem with the measurement of kinetic behavior of photochromic pigments by standard spectrophotometer is relative long time period between individual measurements (5 s) and impossibility of the measurement whole color change during exposure without interruption of illumination of sample during measurement. A method where the sample is exposed in one place and after exposure moved to another place for measurement of actual color, causes a time delay that is dependent on movement velocity between the place of exposure and the place of measurement. In such methodology, the results show poor reproducibility of measurement of the exposure phase of the photochromic color change. That means, the standard commercial spectrophotometers enable off-line measurement of kinetic behavior during exposure period and quasi on-line measurement during 
reversion period. Result is the exposure phase data variation in comparison to small variation of decay phase data, as is shown on Figure 9. Following this knowledge was developed the original on-line experimental system with short time scanning of color change of photochromic samples during growth and decay period of color change. The basic difference between the "LCAM-Photochrom 3" system and a standard spectrophotometer is in the continuous illumination of the sample against a flash source that is used as standard. In such a measuring system, it is possible to use a flash discharge lamp. The reflectance values obtained are independent of whether it is Xenon, Mercury or other strobe source. This construction allows measurement of the color change of the sample in fast scans without disturbing the drift of the light source. The system developed allows $5 \mathrm{~ms}$ intervals between each measuring scan. Nevertheless, it was found that 5 seconds was a sufficient interval for the tested samples.

\section{Results and Discussion}

We have described in previous paragraphs differences between commercial and our experimental measuring system. Figure 9 shows our best results for pigment P1, which we obtained from commercial system when we used special conditions for minimizing of time delay between excitation illumination and measurement. We have obtained individual experimental points during exposition period-growth process of color change intensity via individual exposure of each point. You can see differences between experimental points and model of exposure. As we mentioned, this graph documents best results for adjusted commercial system, the discrepancies was obviously between model and experimental points 3 - 5 times higher, except for time consumption of whole experiment and pure reproducibility (variation 23\% $44 \%$ ) - mainly in dynamic phase of kinetic curve.

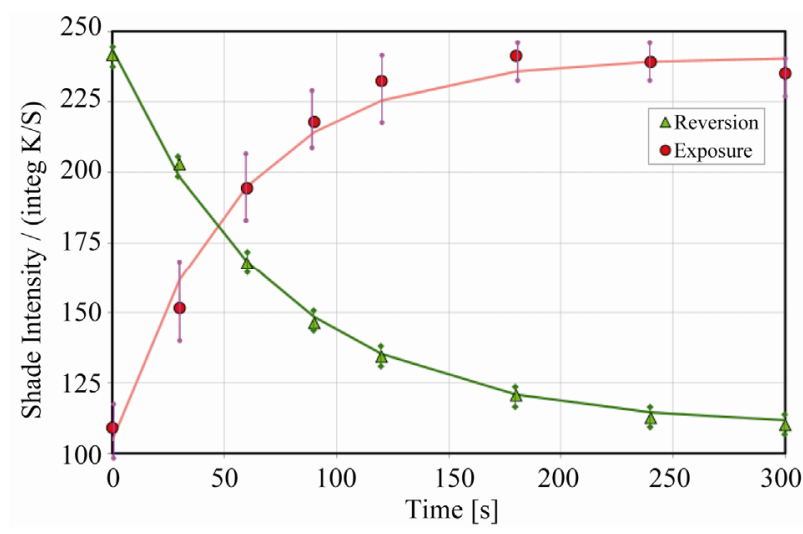

Figure 9. Off-line measurement of growth and decay processes of colour change intensity for pigment $\mathrm{P1}$, intensity of illumination $=714.6 \mathrm{\mu W} \cdot \mathrm{cm}^{-2}$.
On the other hand Figure 10 shows results from our experimental system for same condition of illumination intensity and pigment P1. It is evident that model of experimental points fits better than from standard system, aside from shorter time consumption (20 min against $200 \mathrm{~min}$ ).

Differences between absolute levels of Shade Intensity $I$ (integ $K / S$ ) from each measuring system are occurring by differences between spectral ranges of used systems and calculation. For standard spectrophotometer (SF300UV, Datacolor Int.) previous method of color change intensity calculation based on integration of $K / S$ values per whole visual spectrum range of wavelengths was used.

Main reason for which we made this experiment, it is to design of simple UV textile based sensor. When the relationship between the half-life of color change $t_{1 / 2}$ and the effect of pigment concentration is tested, the result is a practically independent linear relation for the exposure period of photochromic color change as shown in Figure 11. This means that the time of color change during exposure is not influenced by increased concentration of the pigments (a virtually constant value of $t_{1 / 2}$ ).

It can be seen from Figure 12 that the rate of the color change during the reversion phase is slightly dependent on pigment concentration, mainly for the two pigments with a slow rate of color change. Thus, it is possible to conclude that the half-life of color change is, for the exposure period of color change, practically independent of concentration. On the other hand, for the reversion period it can see that there is a decrease of $t_{1 / 2}$ with increasing concentration.

We can see on Figure 12 that speed of color change during reversion phase is slightly dependent on pig-

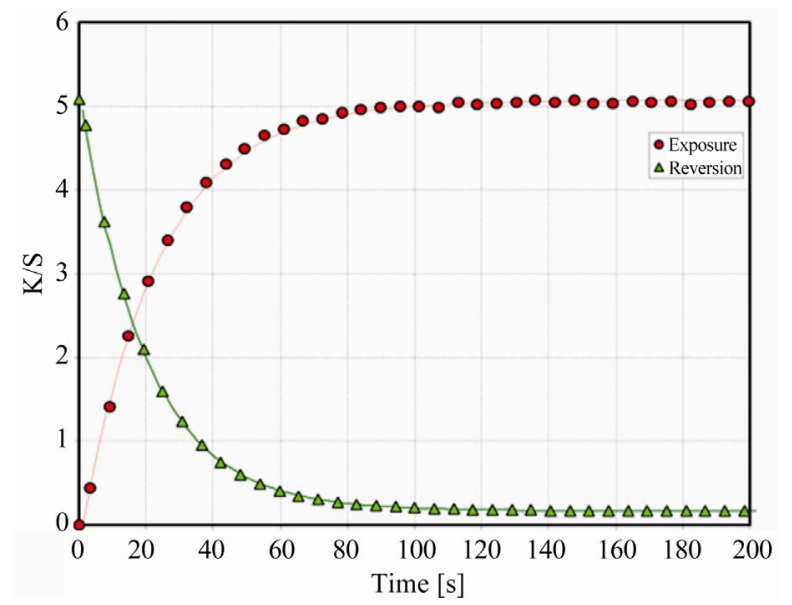

Figure 10. On-line measurement of growth and decay processes of colour change intensity for pigment P1, intensity of illumination $=714.6 \mu \mathrm{W} \cdot \mathrm{cm}^{-2}$. 


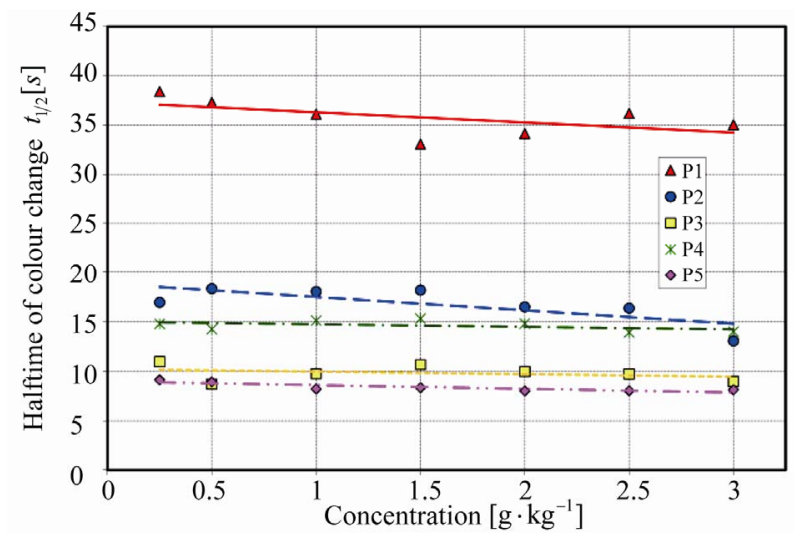

Figure 11. Dependence of Half-life of CCI on concentration of pigments, intensity of illumination $=714.6 \mu \mathrm{W} \cdot \mathrm{cm}^{-2}-$ growth.

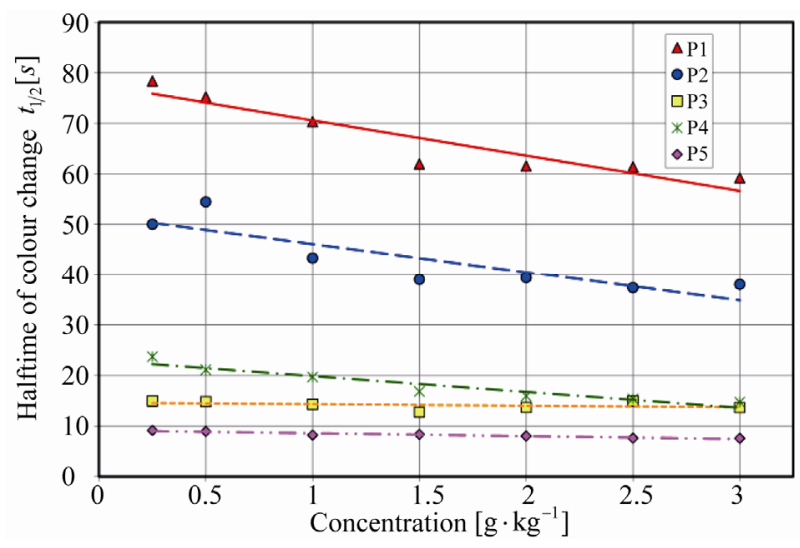

Figure 12. Dependence of Half-life of CCI on concentration of pigments, Intensity of illumination $=714.6 \mu \mathrm{W} \cdot \mathrm{cm}^{-2}$ decay.

ment concentration, mainly for two pigments with slow speed of color change. It is possible to say that half-life of color change is for exposure period practically independent on concentration; on the other side for reversion period we can see decreasing of $t_{1 / 2}$ with increasing of concentration. One explanation, which may be proposed, is that this relationship is based on a faster reconversion to the original chemical structure of the photochromic pigment at higher concentration (likewise light fastness of dyestuff).

A strong negative linear relationship was found between half-life and irradiance for all photochromic pigments. On the Figure 13 is shown, that linear increasing of irradiation intensity affect linear decreasing half-life of color change $t_{1 / 2}$, aside from that have higher illuminetion intensity also on shade intensity alone. That means higher illumination intensity is observed as deeper shade of sensor.

The kinetic study and experimental data sets obtained clearly verify the first order kinetic model for the all

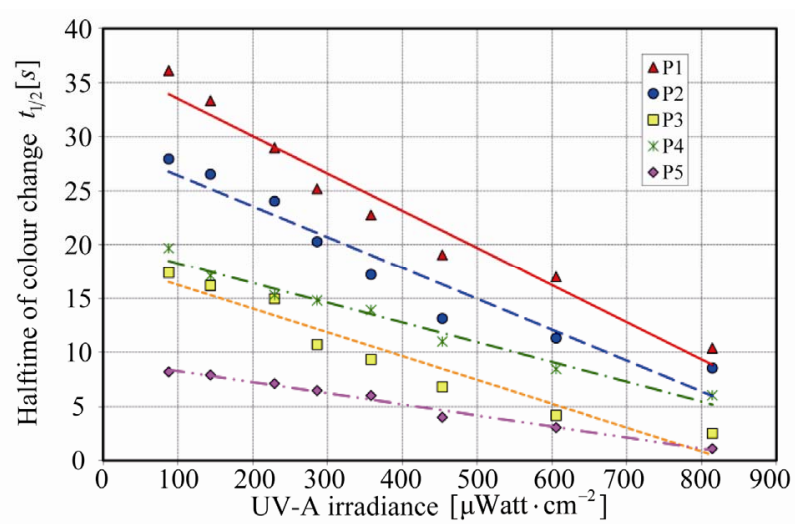

Figure 13. Half-life of color change $t_{1 / 2}$ relation on intensity of UV-A radiation.

tested photochromic pigments. Based on this kinetic model the construction of an optical yield $O y$ formula for the reaction of photochromic textile was proposed:

$$
O y=\int_{0}^{t_{1}} I_{\infty}+\left(I_{0}-I_{\infty}\right) \mathrm{e}^{-k_{E} t} \mathrm{~d} t-\int_{t_{1}}^{t_{2}} I_{0}+\left(I_{\infty}-I_{0}\right) \mathrm{e}^{-k_{R} t} \mathrm{~d} t
$$

As a result of experimental observation and the calculation of the dependence of optical yield $O y$ on UV radiation intensity, it was found that the optical yield of the photochromic reaction $O y$ depends linearly on the UV radiation intensity, as is documented in Figure 14. This correlation could be used for calibration of potential Smart textile sensors with photochromic pigments applied as indicators of UV radiation intensity.

\section{Conclusions}

In our study we showed new aspects of the relationship between UV radiation intensity, color change half-life of exposition and half-life of relaxation, reversion respecttively. These relations demonstrate the possibility of

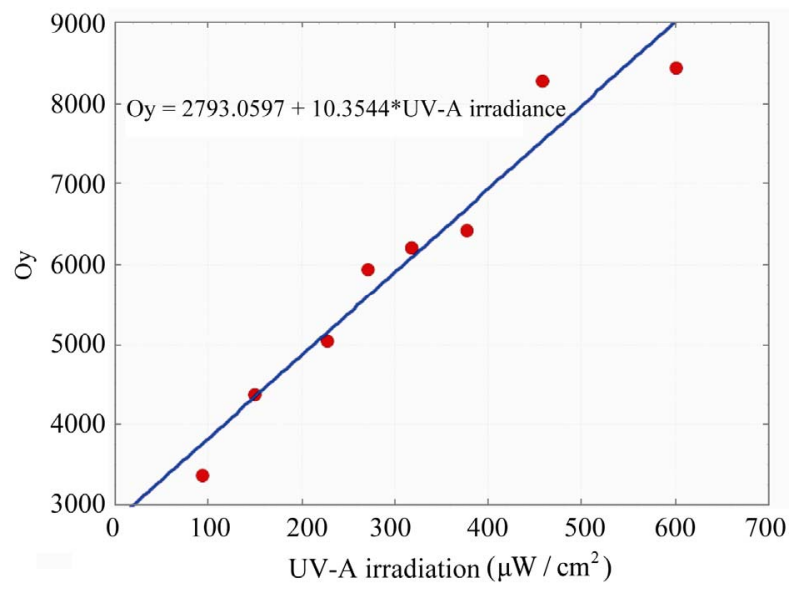

Figure 14. Dependence of $O y$ on UV-A irradiance PPT-P1. 
flexible textile-based sensors construction in the area of radiation intensity identification. We demonstrate also differences between photochromic pigments behavior concerning to spectral sensitivity. First order exponential functions, which are used in kinetic model calculation, fit well the kinetics of color change intensity of photochromic pigments. They give good fits to the growth curves as well as to the relaxation one's. Based on this result, the possibility has been demonstrated in principle that photochromic textiles can be usable for the preparation of a sensorial system, which allows simple visual assessment of the amount of UV radiation. This system can be designed for example as a simple rule scale, where for comparison there is a constant colored part made from UV stable pigments or dyestuffs. Individual parts of the constant scale can be judged on having the same color as the photochromic part at a specific intensity of UV radiation. The observer will be able to estimate the amount of UV radiation corresponding to a color match between the photochromic color changeable part and visual stable part of the textile UV sensor.

\section{Acknowledgements}

We acknowledge support of the Technical University of Liberec.

\section{References}

[1] P. Bamfield, "Chromic Phenomena, Technological Applications of Colour Chemistry," RSC, Cambridge, 2001.

[2] M. Viková and M. Vik, "Colour Shift Photochromic Pigments in Colour Space CIE L*a*b*," Molecular Crystals and Liquid Crystals Science and Technology. Section A. Molecular Crystals and Liquid Crystals, Vol. 431, 2005, pp. 103-116.

[3] K. Vanicek, T. Frei, Z. Litynska and A. Schmalwieser, "UV-Index for the Public," COST-713 Action, Brussels, 1999, pp. 6-18.

[4] J. Groebner, M. Blumthaler, S. Kazadzis, A. Bais, A. Webb, J. Schreder, G. Seckmeyer and D. Rembges, "Quality Assurance of Spectral Solar UV Measurements: Results from 25 UV Monitoring Sites in Europe, 2002 to 2004," Metrologia, Vol. 43, No. 2, 2006, pp. 66-71. doi:10.1088/0026-1394/43/2/S14

[5] R. T. Watson, M. C. Zinyowera, R. H. Moss and D. J. Dokken, "Climate Change 1995, Impacts, Adaptations and Mitigation of Climate Change: Scientific-Technical Analyses," Cambridge University Press, Cambridge, 1996, pp. 562-584.

[6] H. Bouas-Laurent and H. Dürr, "Organic Photochromism," Pure and Applied Chemistry, Vol. 73, No. 4, 2001, pp. 639-665.

[7] J. C. Crano and R. J. Guglielmetti, "Organic Photochromic and Thermochromic Compounds, Vol. 1: Main Pho- tochromic Families," Plenum Press, New York, 1999, pp. $1-9$.

[8] B. L. Feringa, "Molecular switches," Wiley-VCH Verlag, Weinheim, 2001, pp. 1-36.doi:10.1002/3527600329

[9] H. Bouas-Laurent and H. Dürr, "Organic Photochromism," Pure and Applied Chemistry, Vol. 73, No. 4, 2001, pp. 639-665.

[10] R. S. Becker and J. Michl, "Photochromism of Synthetic and Naturally Occurring 2H-Chromenes and 2H-Pyrans," Journal of the Amrican Chemical Society, Vol. 88, No. 24, 1966, pp. 5931-5933. doi:10.1021/ja00976a044

[11] J. Kolc and R. S. Becker, "Proof of Structure of the Colored Photoproducts of Chromenes and Spiropyrans," Journal of Physical Chemistry, Vol. 71, No. 12, 1967, pp. 4045-4047. doi:10.1021/j100871a048

[12] J. Kolc and R. S. Becker, "The Spectroscopy and Photochemistry of Naturally Occurring and Synthetic Chromenes,"Photochemistry and Photobiology, Vol. 12, No. 5, 1970, pp. 383-393. doi:10.1111/j.1751-1097.1970.tb06069.x

[13] C. Lenoble and R. S. Becker, "Photophysics, Photochemistry and Kinetics of Photochromic $2 H$-Pyrans and Chromenes," Journal of Photochemistry, Vol. 33, No. 2, 1986, pp. 187-197.doi:10.1016/0047-2670(86)87033-2

[14] D. Kühn, H. Balli and U. E. Steiner, "Kinetic Study of the Photodecoloration Mechanism of an Inversely Photochromic Class of Compounds Forming Spiropyran Analogues," Journal of Photochemistry and Photobiology A: Chemistry, Vol. 61, No. 1, 1991, pp. 99-112.

[15] B. Van Gemert and D. Knowles, "Photochromism of Diarylnaphthopyrans," PPG Informations, Vol. 1, 1995, pp. 1117.

[16] J. C. Crano, T. Flood, D. Knowles, A. Kumar and B. van Gemert, "Photochromic Compounds: Chemistry and Application in Ophthalmic Lenses," Pure and Applied Chemistry, Vol. 68, No. 7, 1996, pp. 1395-1398. doi:/10.1351/pac199668071395

[17] G. Favaro, U. Mazzucato, G. Ottavi and R. S. Becker, "Kinetic Analysis of the Photochromic Behavior of a Naturally Occurring Chromene (Lapachenole) Under Steady Irradiation," Molecular Crystals and Liquid Crystals Science and Technology. Section A. Molecular Crystals and Liquid Crystals, Vol. 298, No. 1, 1997, pp. 137-144. doi:10.1080/10587259708036153

[18] G. Ottavi, G. Favaro and V. Malatesta, "Spectrokinetic Study of 2,2-Diphenyl-5,6-benzo(2H) Chromene: A Thermoreversible and Photoreversible Photochromic System," Journal of Photochemistry Photobiology A: Chemistry, Vol. 115, 1998, pp. 123-128.

[19] J. K. Hurst, K. Giertz, R. F. Khairutdinov, E. N. Voloshina and V. I. Minkin, "Photochromism of Spirooxazines in Homogeneous Solution and Phospholipid Liposomes," Journal of American Chemical Society, Vol. 120, No. 49, 1998, pp. 12707-12713. doi:10.1021/ja9825985

[20] S. Delbaere, B. Luccioni-Houze, Ch. Bochu, Y. Teral, M. Campredon and G. Vermeersch, "Kinetic and Structural 
Studies of the Photochromic Process of $3 H$-Naphthopyrans by UV and NMR Spectroscopy," Journal of the Chemical Society, Perkin Transactions 2, No. 5, 1998, pp. 1153-1157. doi:10.1039/a800906f

[21] M. Zayat and D. Levy, "Photochromic Naphthopyrans in Sol-Gel Ormosil Coatings," Journal of Materials Chemistry, Vol. 13, No. 4, 2003, pp. 727-730. doi:10.1039/b211759b

[22] P. J. Coelho, M. A. Salvador, B. M. HeronL and M. Carvalho, "Spectrokinetic Studies on New Bi-Photochromic Molecules Containing Two Naphthopyran Entities," Tetrahedron, Vol. 61, No. 49, 2005, 11730-11743. doi:10.1016/j.tet.2005.09.035

[23] G. H. Brown, (Ed.), "Techniques of Chemistry, Vol. III, Photochromism," John Wiley \& Sons, New York, 1971.

[24] A. V. Eltsov, (Ed.), "Organic Photochromes," Plenum Publishing Corporation, New York, 1990.

[25] M. Hua, S. Kawauchi, M. Satoha, J. Komiyamaa, J. Watanabea, S. Kobatake and M. Irie, "Two-Photon Photochromism of Two Simple Chromene Derivatives," Journal of Photochemistry and Photobiology A: Chemistry, Vol. 150, No. 1-3, 2002, pp. 131-141. doi:10.1016/S1010-6030(02)00136-3

[26] S. Pu, H. Tang, B. Chen, J. Xu and W. Huang, "Photochromic Diarylethene for Two-Photon 3D Optical Storage," Materials Letters, Vol. 60, No. 29-30, 2006, pp. 3553-
3557. doi:10.1016/j.matlet.2006.03.050

[27] Y. Feng, Y. Yan, S. Wang, Z. Zhu, S. Qian and H. Tian, "Photochromic Thiophene Oligomers Based on Bisthienylethene: Syntheses, Photochromic and Two-Photon Properties," Journal of Materials Chemistry, Vol. 16, No. 37, 2006, pp. 3685-3692.doi:10.1039/b608545h

[28] M. Maafi, "Useful Spectrokinetic Methods for the Investigation of Photochromic and Thermo-Photochromic Spiropyrans," Molecules, Vol. 13, No. 9, 2008, pp. 22602302. doi:/10.3390/molecules 13092260

[29] H. Dürr and H. Bouas-Laurent, "Photochromism, Molecules and Systems," Elsevier, New York, 1990.

[30] N. Ohta and A. R. Robertson, "Colorimetry Funamental and Applications," John Wiley \& Sons, Chichester, 2005. doi:10.1002/0470094745

[31] R. McDonald, "Colour Physics for Industry," 2nd Edition, SDC, Bradford, 1997

[32] M. Vikova, "Photochromic Textiles," Ph.D. Thesis, HeriotWatt University, Edinburgh, 2011.

[33] M. Viková and M. Vik, "Smart Textile Sensors for Indication of UV Radiation," AUTEX 2006 World Textile Conference, Raleigh, 11-14 June 2006.

[34] M. Viková and M. Vik, "Measurement of Photochromic textiles," International Symposium on Photochromism, Vancouver, 7-10 October 2007. 